\title{
A Case Study of Improvement Activities Using Work Motivation Theory in ITIL Implementation
}

\author{
Hitoshi Tsunoda*, Yasunobu Kino \\ Graduate School of Business Science, University of Tsukuba, Tokyo, Japan. \\ * Corresponding author. Tel.: +81-90-2757-2144; email: jin.tsunoda@gmail.com \\ Manuscript submitted October 15, 2017; accepted November 10, 2017. \\ doi: 10.17706/ijeeee.2018.8.4.219-226
}

\begin{abstract}
In recent years, ITIL (Information Technology Infrastructure Library) has become a de facto world standard in the field of system operations of enterprise information systems. However, ITIL implementation has several issues, one of which is improving motivation of employees of the system operations department. In light of this issue, purpose of the study is to implement motivation improvement measures for ITIL implementation and confirm the effectiveness of such measures. We propose improving activities using work motivation theory for that purpose. In this paper, we report the case of the system operations department of a company applying the method and confirm the effectiveness of the method. Our findings show that among three categories of work motivation theory (achievement orientation, competition orientation, and cooperation orientation), the effect of cooperation orientation is high and the effect of competition orientation is low. In this paper, we encourage practitioners to promote cooperation orientation, such as promoting team activities, as a motivation improvement measure.
\end{abstract}

Key words: Enterprise information systems, ITIL, work motivation theory, improvement activities.

\section{Introduction}

In the field of system operations of enterprise information systems, higher quality is required each year. For that reason, the IT department of each company intends to improve the quality of system operations by introducing ITIL [1]. ITIL is the best practice in system operations, which was published by the British government in 1989, and is now considered the de facto world standard. Marrone et al. [2] shows the results of the survey that $48 \%$ of firms have introduced ITIL by questionnaire to 623 companies in US / UK / Germany / Australia. ITIL consists of 26 processes, such as incident management and change management, encourages the introduction and continuous improvement of processes. However, ITIL implementation (introduction, establishment, and improvement) is very difficult and has several issues. One of those issues is to improve the motivation of employees of the system operations department. System operations has a lot of routine work and daily work tends to be inert, which makes it is difficult to maintain employees' motivation.

The purpose of this paper is to implement motivation improvement measures for ITIL implementation and confirm its effectiveness in light of the above-described background and issues. We propose improving activities using work motivation theory [3]. Brrick et al. [4] classified work motivation into three categories (achievement-oriented, competitive-oriented, cooperative-oriented). In this research, we propose to create motivation improvement measures using the three categories, and evaluate measures after implementing 
that.

In this paper, we report examples of the system operations department of a company applying these methods, confirm the effectiveness of the methods, and describe implications obtained through analysis. The effectiveness of the method is confirmed by a questionnaire survey of employees of the system operations department. As an example, we will focus on the practice of the information systems subsidiary of Japan's largest insurance company (hereinafter referred to as Company A). This paper contributes to the accumulation of practical data of work motivation theory for academic purposes. Practically, it is useful for the system operations department of companies as it proposes the method of ITIL implementation.

The structure of this paper is as follows. After reviewing related work in Section 2, we propose a method of motivation improvement in Section 3, report a case study applying the proposed contents in Section 4, describe implications in Section 5, and summarize our findings in Section 6. We used ITIL V3 (2011 version), which is the latest version at the time this paper was written.

\section{Related Work}

\subsection{CSF of ITIL Implementation}

According to the literature review, in recent years, the focus of research on ITIL implementation is mainly CSF (Criteria Success Factor), benefits, motives, and implementation status [5]-[7]. Among them, research on CSF is the most popular, followed by benefits. This indicates a high level of interest in learning how to utilize CSF to introduce, fix, and improve ITIL, and what kind of results are produced by ITIL implementation. Motivation improvement, which is the focus of this paper, is one of ITIL's CSFs. While motivation improvement in ITIL implementation is an important CSF, the research only focuses on it importance, not how to improve motivation.

\subsection{Continuous Improvement}

ITIL consists of 26 processes, which are described in 5 "core books" (service strategy, service design, service operation, service transition, and continuous service improvement) [1]. One of the five core books is about continuous improvement, which shows that ITIL emphasizes improvement activities. The key concept of ITIL is the steady implementation of PDCA (plan, do, check, and action), and, therefore, continuous improvement is indispensable. Continuous improvement is also regarded as important in Japanese companies, particularly in the manufacturing industry. Toyota is one company that utilizes continuous improvement in the automobile manufacturing industry, and it is one of the components of the Toyota Production System (TPS) [8]. The point of continuous improvement in that company is to promptly solve small problems at the manufacturing site with teamwork. This paper was also written with reference to this point.

\subsection{Work Motivation Theory}

The research history of motivation theory is old, and it is studied in various fields, such as business science, psychology, and pedagogy. One motivation in business is called work motivation. Mitchell [3] defines work motivation as "a psychological process of directing, activating, and maintaining behavior towards the target." In recent years, this definition has been used [9], [10]. Barrick et al. [4] proposed a scale to measure work motivation, as standardly defined, with a view to measuring dynamic three aspects. Specifically, it is necessary to provide achievement-oriented motivation to accomplish employee's duties, competition-oriented motivation to fulfill duties at a higher level than that of colleagues, and cooperation-oriented motivation to cooperate with colleagues. We will build up the proposal based on research by Barrick et al. 


\subsection{Position of This Paper}

The position of this paper will be explained with reference to Fig. 1. In system operations departments, we will implement the PDCA cycle of the ITIL process to achieve the benefits of system operations (Fig. 1 (C)). In order to implement the ITIL PDCA cycle nicely, some CSFs including top management support are required. Staff motivation improvement is one of those CSFs (Fig. 1 [B]). There are several methods to improve the motivation of the staff. One of them is the use of the process improvement activity (Fig. 1 [A]). In this research, we focus on Fig. 1[A], and propose a method for that. We expect process improvement activities to contribute to improvement of motivation of staff. This research contributes to the work motivation theory in academia and proposes practical methods for practitioners.

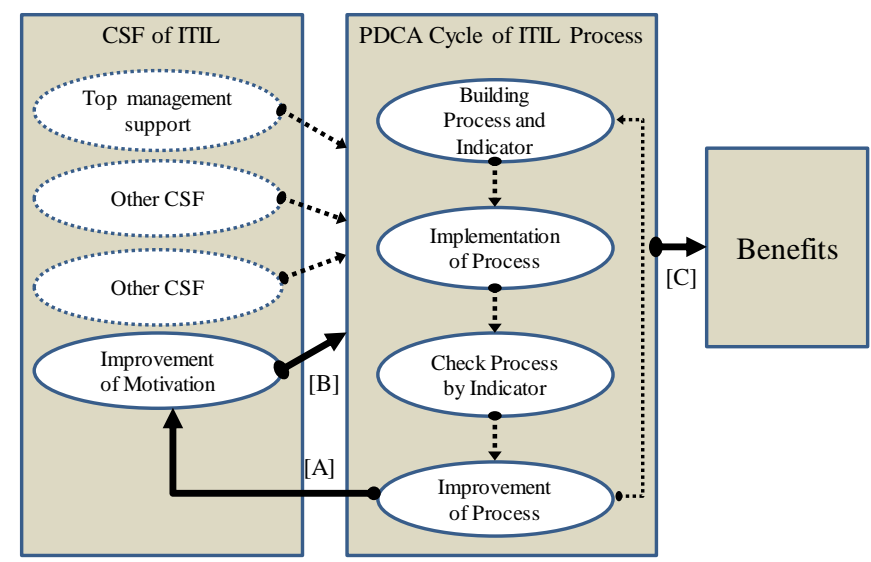

Fig. 1. Model of this study.

\section{Proposal}

In this paper, we propose promoting improvement activities that apply the work motivation theory for the purpose of motivating employees of the system operations department of a company. The characteristic of this proposal is two-fold: (1) use of improvement activities and (2) application of work motivation theory. Both characteristics have different practice perspectives. The use of improvement activities corresponds to HOW to implement policies. On the other hand, application of the work motivation theory relates to WHAT to include in work motivation measures. Details of both are described below.

\subsection{Using Improvement Activities}

Normally, it is common to improve motivation to encourage improvement activities. However, in this paper, we propose to use improvement activities to improve motivation. To put it in extreme terms, even if you ignore the benefits of improvement activities (such as efficiency), if you improve motivation, we consider the practice a success.

\subsection{Application of Work Motivation Theory}

We utilized the work motivation theory to examine the content of motivation improvement measures of employees of the system operations department. Specifically, using Barrick et al.'s theory, we examined the measures from the three perspectives of achievement orientation, competition orientation, and cooperation orientation. Also, before and after implementing the measures, we conducted a questionnaire survey, using the questions proposed by Barrick et al., which included 15 questions in each of the three perspectives, for 45 questions in total. Based on the questionnaire survey, we could determine which of the three categories had to be emphasized and what measures had to be considered. 


\section{Case Study}

\subsection{Practice of Improvement Activities}

Company A is an information system subsidiary of the largest insurance company in Japan. Its main businesses are system development and system operations, which have 1360 employees. With its financial liberalization in 1998 in Japan, the insurance company expanded rapidly, which complicated its information systems and led to frequent system failures in 2000. This was a management issue and the company implemented various countermeasures in response. In 2001, the company introduced ITIL, and all employees in the system operations department were required to acquire "ITIL Foundation" qualifications. In 2006, the company also acquired ISO 20000 and aimed to strengthen the operations department. The recent issue in the company's system operations department is maintaining high operational quality and improving motivation to support it. This is because there are many routine activities in system operations, which makes it difficult to improve motivation. Also, more than 10 years have passed since ITIL was introduced at the company, and many of the employees who were at the company when it was introduced have left. Many employees are only now understanding the significance and purpose of the process. Therefore, the company needed to improve employee motivation. Accordingly, we implemented an in-house campaign called "Small and Quick!" in the system operations department of Company A. "Small and quick!" means to carry out small improvement activities quickly. The purpose of these activities is to improve motivation.

\subsection{Motivation Improvement Measures}

In the system operations department of Company A, "Small and Quick!" was started in July 2017. First, we examined motivation improvement measures using the KJ method [11]. The KJ method is a method for creating ideas that was invented by Kawakita. Five employees participated in the KJ method, including 2 managers and 3 members in the system operations department. We reviewed the KJ method and the work motivation theory at the beginning, and then those proficient in the KJ method took on the role of facilitators and devised measures. The process, conducted in the company's conference room, took approximately four hours. Table 1 shows the motivation improvement measures developed through the KJ method. Measures are devised in a well-balanced manner for each category of the work motivation theory, and there are three measures for each of the three categories, for a total of nine measures. Second, from July 2017 to September 2017, we implemented motivation improvement measures, one after another. The person responsible for the project was the head of the system operations department (Executive Officer) and project leader was a member of Project Management Office (PMO). PMO is an organization under the direct control of the department head. Three employees belong to the PMO, and risk management, such as quality, cost, and delivery date of each project in the headquarters, is carried out. Details of the measures that were implemented are described below.

Table 1. List of Measure to Improve Motivation

\begin{tabular}{|c|l|}
\hline Category & \multicolumn{1}{|c|}{ Measures } \\
\hline \multirow{3}{*}{ Achievement } & $\begin{array}{l}\text { Message from the Executive Officer. } \\
\text { MBO \& Visibility of Achievement Status of Each Activity. } \\
\text { Praise by the Executive Officer. }\end{array}$ \\
\hline \multirow{3}{*}{ Competition } & $\begin{array}{l}\text { Presentation Conference Held by All Members. } \\
\text { Establishment of Executive Officer's Award. } \\
\text { Presentation of Excellent Activities at the Board Meeting. }\end{array}$ \\
\hline \multirow{2}{*}{ Cooperation } & $\begin{array}{l}\text { Activities as a Team. } \\
\text { Praise as a Team. } \\
\text { Support by Managers }\end{array}$ \\
\hline
\end{tabular}




\subsubsection{Achievement}

First, the head of the department sent an e-mail message to all employees. The purpose of this e-mail was to disseminate the expectation for employees, points of practice, etc. For example, for "Small and Quick!" we start by implementing small improvement activities quickly, cooperating with each other in team activities in small groups, describing the contents of measures to be implemented, etc. Second, the department created Management by Objectives (MBO). Twelve teams were created to devise improvement activities, and 132 activities were named. The PMO listed them and managed the progress. The department head aimed to timely praise employees at various places, such as in meeting rooms and elevators, when employees participated in the team activities, even if the results of the activities were small.

\subsubsection{Competition}

To encourage competition, "Presentation Meeting" was held to present excellent practices to the department head. In selecting excellent practices, we emphasized that every person contributed wisdom to his or her team and motivated other teams. In doing this, the persons in charge created a sense of self-utility, that is, "I can do it". Executive officer established "Executive Officer Award" and gave an excellent team the award. In addition, the team also made a presentation at the board meeting including president.

\subsubsection{Cooperation}

Cooperation is also important for improving motivation. This practice promoted team activities and did not allow individual participation. This was to foster a cooperative culture. Furthermore, because it is important to establish a good relationship between members and managers we worked to strengthen communication between superiors and subordinates, such as encouraging support from the section managers at key times.

\subsubsection{From exogenous motive to intrinsic motive}

The above various measures are primarily externally motivated in the theory of exogenous/intrinsic motivation of Deci [12], with the department head and PMO leading the employees. In order to further motivate, it is important, as a next step, for each member to internalize these measures. There are three elements of intrinsic motivation - autonomy, competence, and relationship. We decided to implement policies relating to autonomy. Specifically, administrative measures, such as MBO, were implemented by the PMO during the first one months, however after that they urged each team to autonomously implement these measures.

\subsection{Evaluation}

In order to evaluate motivation improvement measures, we conducted a survey on transfer (change in consciousness and behavior) located at level 3 of Kirkpatrick's four-step model [13], which is a representative evaluation method for human resource development. The subjects to be evaluated were classified into the three categories of work motivation theory, and the change in consciousness before and after the motivation improvement measures was verified.

\subsubsection{Method}

We conducted a questionnaire survey for all employees in September 2017, after we had implemented motivation improvement measures for two months. The survey was conducted in the company's conference room after explaining the purpose of the survey and how to complete it. The questions are shown in Table 2. With reference to Barrick et al., there are nine questions, with three questions in each of the three categories. Respondents indicated their degree of agreement with each statement on a 5-point Likert scale ( 5 = agree, $4=$ somewhat agree, $3=$ neither agree nor disagree, $2=$ somewhat disagree, $1=$ disagree $)$.

\subsubsection{Results}

Of the employees we targeted, 45 respondents, excluding those on vacation, on business trips, etc., 
provided responses. Of the 45 respondents, 13 were managers and 32 were non-managers. Tables 3 to 5 show the aggregate results of responses. Table 3 shows the results of all the subjects, Table 4 shows the results of managers, and Table 5 shows the results of non-managers. In order to ascertain whether the difference between the average points before and after the implementation of motivation improvement measures is statistically significant, a two-tailed t test was conducted $(* * *$ indicates significance ate $0.1 \%$, ** indicates significance at $1 \%,{ }^{*}$ indicates significance at $5 \%$ ). As a result, we confirmed that there were significant differencies within $1 \%$, excluding competition orientation of the managers.

Table 2. Items of the Questionnaire Survey

\begin{tabular}{|c|c|}
\hline Category & Items \\
\hline Achievement & $\begin{array}{l}\text { Q1) I feel meaningful in completing the work given to me. } \\
\text { Q2) I have a desire to carry out as much work as possible. } \\
\text { Q3) I am working with a single mind to fulfill my duties. }\end{array}$ \\
\hline Competition & $\begin{array}{l}\text { Q4) I'd like to achieve better results than my colleagues. } \\
\text { Q5) I do not want to lose to my colleagues. } \\
\text { Q6) I want to be recognized by my colleagues and my boss. }\end{array}$ \\
\hline Cooperation & $\begin{array}{l}\text { Q7) I'd like to work with colleagues cooperatively. } \\
\text { Q8) I want to build a good relationship with my colleagues. } \\
\text { Q9) I am thinking of becoming a member of team. }\end{array}$ \\
\hline
\end{tabular}

Table 3. Result of the Questionnaire Survey

\begin{tabular}{|c|cc|cc|c|c|c|}
\hline \multirow{2}{*}{$\mathrm{n}=45$} & \multicolumn{2}{|c|}{ Before Implementation } & \multicolumn{2}{|c|}{ After Implementation } & $\begin{array}{c}\text { Difference } \\
\text { (=M2-M1) }\end{array}$ & t-value & p-value \\
\cline { 2 - 7 } & $\mathrm{M} 1$ & $\mathrm{SD} 1$ & $\mathrm{M} 2$ & $\mathrm{SD} 2$ & & \\
\hline Achievement & 3.80 & 0.79 & 4.16 & 0.73 & 0.36 & 7.11 & $* * *$ \\
Competition & 3.14 & 0.84 & 3.35 & 0.98 & 0.21 & 4.40 & $* * *$ \\
Cooperation & 3.90 & 0.83 & 4.28 & 0.78 & 0.38 & 6.93 & $* * *$ \\
\hline
\end{tabular}

Table 4. Result of the Questionnaire Survey (Manager)

\begin{tabular}{|c|cc|cc|c|c|c|}
\hline \multirow{2}{*}{$\mathrm{n}=13$} & \multicolumn{2}{|c|}{ Before Implementation } & \multicolumn{2}{|c|}{ After Implementation } & $\begin{array}{c}\text { Difference } \\
\text { (=M2-M 1) }\end{array}$ & t-value & p-value \\
\cline { 2 - 7 } & $\mathrm{M} 1$ & $\mathrm{SD} 1$ & $\mathrm{M} 2$ & $\mathrm{SD} 2$ & & \\
\hline Achievement & 3.52 & 0.83 & 4.12 & 0.77 & 0.6 & 5.80 & $* * *$ \\
Competition & 3.38 & 0.73 & 3.52 & 0.89 & 0.14 & 1.64 & n.s. \\
Cooperation & 3.74 & 0.77 & 4.40 & 0.63 & 0.66 & 6.29 & $* * *$ \\
\hline
\end{tabular}

Table 5. Result of the Questionnaire Survey (Non Manager)

\begin{tabular}{|c|c|c|c|c|c|c|c|}
\hline \multirow{2}{*}{$\mathrm{n}=32$} & \multicolumn{2}{|c|}{ Before Implementation } & \multicolumn{2}{|c|}{ After Implementation } & \multirow{2}{*}{$\begin{array}{l}\text { Difference } \\
(=\mathrm{M} 2-\mathrm{M} 1)\end{array}$} & \multirow{2}{*}{ t-value } & \multirow{2}{*}{$\mathrm{p}$-value } \\
\hline & M1 & SD1 & M2 & $\mathrm{SD} 2$ & & & \\
\hline Achievement & 3.92 & 0.74 & 4.18 & 0.72 & 0.26 & 4.70 & $* * *$ \\
\hline Competition & 3.03 & 0.87 & 3.27 & 1.01 & 0.24 & 4.22 & $* * *$ \\
\hline Cooperation & 3.97 & 0.85 & 4.23 & 0.84 & 0.26 & 4.23 & $* * *$ \\
\hline
\end{tabular}

\section{Implication}

We will discuss the effectiveness of motivation improvement measures based on the case study of Section 4. As can be seen from Table 3, the motivation is significantly improved for all three categories of work motivation theory, and the motivation improvement measures in the case study are considered to be successful. From highest to lowest, the average value after implementation was cooperation orientation 
(4.28), followed by achievement orientation (4.16), and then competition orientation (3.35). Next, the difference between the average values before and after implementation is in the same order: cooperation orientation (0.38), achievement orientation (0.36), and competition orientation (0.21). Fig.2 is a graph of Table 3. For cooperation orientation, both the average value and the change in value before and after implementation are high, which shows that cooperation orientation was the most effective. Continuous improvement of the Toyota production system (TPM) shown in the related works is also active in the team and it is generally inferred that cooperation with the members of the same team is meaningful in improving activities, and motivation of members is maintained by that activities. On the other hand, competitive orientation is lowest in both average and difference. Especially in managerial positions, there was no significant difference (Table 4). From the above, it is inferred that a higher effect can be expected cooperation orientation is emphasized when considering measures to improve motivation.

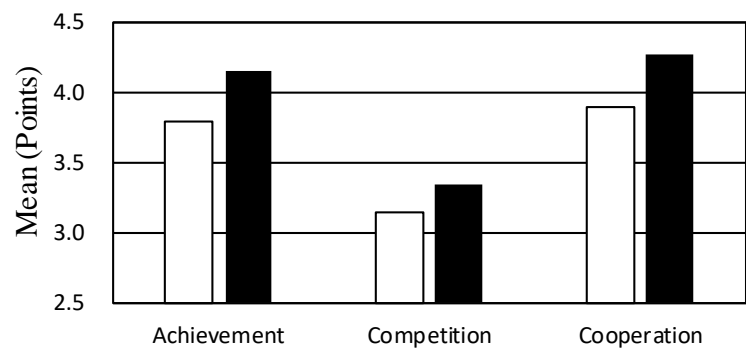

Fig. 2. Result of the questionnaire survey (before: white, after: black).

Next, to investigate the question items validity, Cronbach's $\alpha$ was calculated for each of the three categories (Table 6). As a result, competition orientation and cooperation orientation were $\alpha>0.8$ and the internal consistency was high, however the achievement orientation was not high $(\alpha=0.688<0.8)$. When using question items in the future, it is recommend that the question items of achievement orientation are modified.

Table 6. Cronbach' $\alpha$ of Question Items

\begin{tabular}{|c|c|c|}
\hline Achievement & Competition & Cooperation \\
\hline 0.688 & 0.891 & 0.844 \\
\hline
\end{tabular}

\section{Conclusion}

The purpose of this paper was to implement motivation improvement measures for ITIL implementation and confirm the effectiveness of such measures. For that purpose, we proposed improvement activities using work motivation theory and applied them to the case to confirm their effectiveness. As a result, it was found that if appropriate measures are implemented, all three categories of work motivation theory (achievement orientation, competition orientation, and cooperation orientation) are improved. However, among the three categories, cooperation orientation was the highest and competition orientation was the lowest. Thus, when considering measures to improve motivation, it is inferred that a higher effect can be expected if the content promotes cooperation orientation. This paper contributes to the accumulation of practical data of work motivation theory for academic purposes. This paper is practically useful for the system operations department of each company by proposing the method of ITIL implementation. The limit of this paper is that studies the case of one company and generalization is insufficient. It is expected that future generations will be improved by applying the method of this paper to many cases. 


\section{Acknowledgment}

We would like to express our deepest appreciation to the members of system operations department of Company A, who cooperated in the investigation of this research.

\section{References}

[1] Office of Government Commerce. (2011). ITIL@2011 Edition: Service Strategy, Service Design, Service Transition, Service Operation, Continual Service Improvement. TSO.

[2] Marrone, M., Gacenga, F., Cater-Steel, A., \& Kolbe, L. (2014). IT service management: A cross-national study of ITIL adoption. Communications of the Association for Information Systems, 34(49), 865-892.

[3] Mitchell, T. R. (1997). Matching motivational strategies with organizational contexts. Research in Organizational Behavior, 19, 57-149.

[4] Barrick, M. R., Stewart, G. L., \& Piotrowski, M. (2002). Personality and job performance: Test of the mediating effects of motivation among sales representatives. Journal of Applied Psychology, 87(1), 43-51.

[5] Iden, J., \& Eikebrokk, T. R. (2013). Implementing IT service management: A systematic literature review. International Journal of Information Management, 33(3), 512-523.

[6] Barros, M., Salles, C., Gomes, C., Silva, R., \& Costa, H. (2015). Mapping of the scientific production on the ITIL application published in the national and international literature. Procedia Computer Science, 55, 102-111.

[7] Ahmad, N., Amer, T., Qutaifan, F., \& Alhilali, A. (2013). Technology adoption model and a road map to successful implementation. Journal of Enterprise Information Management, 26(5), 553-576.

[8] Ohno, T. (1988). Toyota Production System: Beyond Large-Scale Production. CRC Press.

[9] Craig, C., \& Pinder, C. C. (2015). Work Motivation in Organizational Behavior. Routledge.

[10] Kanfer, R., Chen, G., \& Pritchard, R. D. (2012). Work Motivation: Past, Present and Future. Routledge.

[11] Kawakita, J. (1975). The KJ Method - A Scientific Approach to Problem Solving. Kawakita Research Institute, Tokyo.

[12] Deci, E. L. (1971). Effects of externally mediated rewards on intrinsic motivation. Journal of Personality and Social Psychology, 18(1), 105-115.

[13] Kirkpatrick, D. (1994). Evaluating Training Programs: The Four Levels. San Francisco Berrett-Koehler.

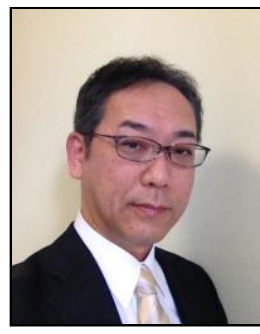

Hitoshi Tsunoda is a Ph.D candidate of Graduate School of Business at University of Tsukuba in Japan. He received his master degree from Tohoku University and Waseda University in Japan. His research focuses on enterprise information systems and IT service management. He is one of the head of IT department in the largest insurance company in Japan, and has CISA (Certificated Information System Auditor).

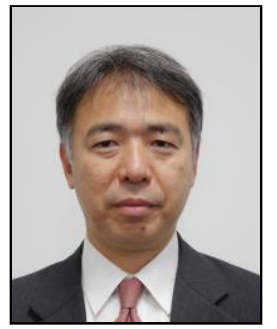

Yasunobu Kino is an associate professor of Graduate School of Business at University of Tsukuba in Japan. He received his Ph.D degree (Systems management) from University of Tsukuba. His research focuses on project management and systems design. He worked at IBM Japan Ltd., and was a project manager of system development in finance companies and manufacturing companies. 